
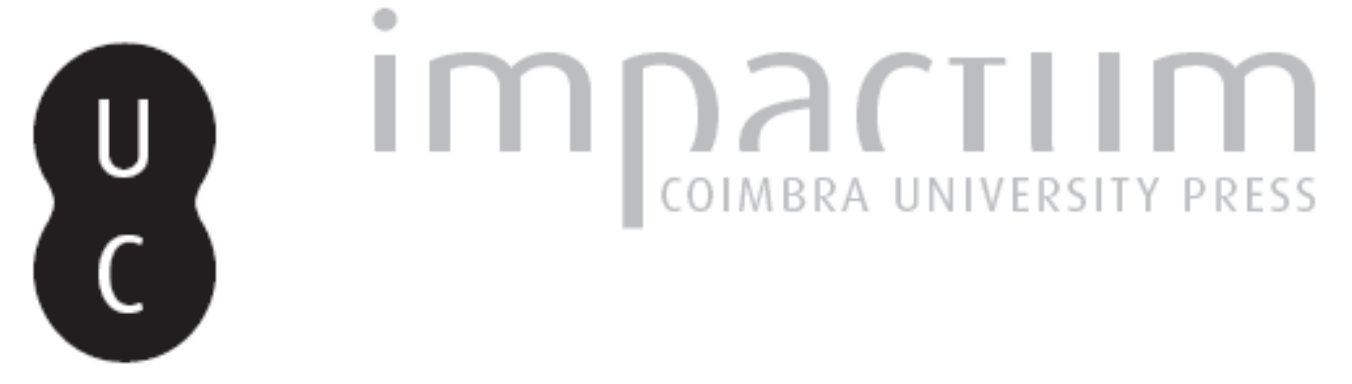

\title{
Área funerária romana em Évora: dos restos ósseos aos rituais funerários
}
Autor(es): $\quad$ Fernandes, Teresa Matos; Paredes, Joana; Rebocho, Lurdes; Lopes, Maria Helena; Janeirinho, Vânia

Publicado por: CIAS - Centro de Investigação em Antropologia e Saúde

URL persistente:

URI:http://hdl.handle.net/10316.2/29601

DOI:

DOI:http://dx.doi.org/10.14195/2182-7982_29_12

Accessed : $\quad$ 26-Apr-2023 10:42:23

A navegação consulta e descarregamento dos títulos inseridos nas Bibliotecas Digitais UC Digitalis, UC Pombalina e UC Impactum, pressupõem a aceitação plena e sem reservas dos Termos e Condições de Uso destas Bibliotecas Digitais, disponíveis em https://digitalis.uc.pt/pt-pt/termos.

Conforme exposto nos referidos Termos e Condições de Uso, o descarregamento de títulos de acesso restrito requer uma licença válida de autorização devendo o utilizador aceder ao(s) documento(s) a partir de um endereço de IP da instituição detentora da supramencionada licença.

Ao utilizador é apenas permitido o descarregamento para uso pessoal, pelo que o emprego do(s) título(s) descarregado(s) para outro fim, designadamente comercial, carece de autorização do respetivo autor ou editor da obra.

Na medida em que todas as obras da UC Digitalis se encontram protegidas pelo Código do Direito de Autor e Direitos Conexos e demais legislação aplicável, toda a cópia, parcial ou total, deste documento, nos casos em que é legalmente admitida, deverá conter ou fazer-se acompanhar por este aviso.

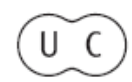




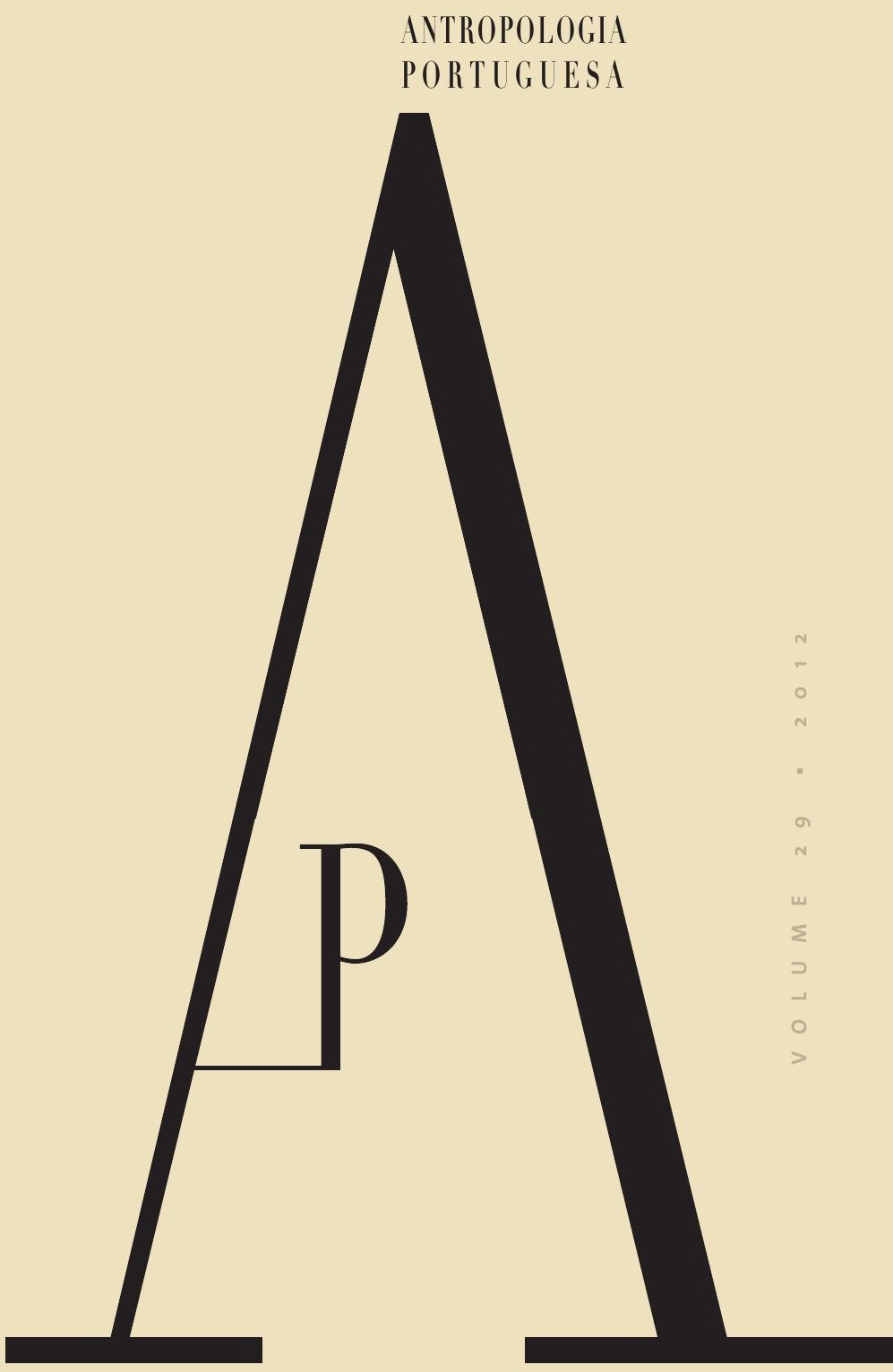

CENTRO DE

INVESTIGAÇ̃̃O

EI ANTROPOLOGIA

E SAÚDE

UNIVERSIDADE

DE COIMBRA 


\section{Área funerária romana em Évora: dos restos ósseos aos rituais funerários}

\section{Teresa Matos Fernandes ${ }^{1,2}$, Joana Paredes', Lurdes Rebocho', Maria Helena Lopes' ${ }^{1}$, Vânia Janeirinh ${ }^{1}{ }^{1}$}

labuevora@gmail.com

tmf@uevora.pt

Resumo Após intervenção parcial numa área funerária romana (datada entre os sécs. I e II d.C.) identificada em Évora, foi analisado em laboratório o conteúdo osteológico e odontológico de 11 estruturas funerárias de cremação e uma de inumação. Cruzando os resultados da análise antropológica com o espólio arqueológico associado foram obtidas informações em torno dos rituais funerários, nomeadamente os associados à cremação, e traçado o perfil biológico dos indivíduos. Verificou-se uma alta variabilidade na construção e utilização das estruturas funerárias, quer na tipologia das mesmas, quer no pro-

\begin{abstract}
The content of 11 cremation funeral structures and one inhumation, founded during an intervention on a roman necropolis (dated between $1^{\text {st }}$ and $2^{\text {nd }}$ century), localized on the Gabriel Pereira's High School (Évora, Portugal), was analysed in laboratory, giving emphasis to the osteological and odontological material. When the results from the direct observation were crossed with metric data and archeological material associated, several informations were obtained concerning burial rituals (especially when associated to cremation) and individual biological profiles, as much as the preservation state allowed.
\end{abstract}

\footnotetext{
${ }^{1}$ Laboratório de Antropologia Biológica, Universidade de Évora, Portugal

${ }^{2}$ Centro de Investigação em Antropologia e Saúde (CIAS), Departamento de Ciências da Vida, Universidade de Coimbra, Portugal
} 
cessamento pós-crematório, fenómeno comum em áreas funerárias romanas de Hispania, tal como no restante espaço do Império romano. Não foi identificada qualquer relação entre o tipo de estruturas, as oferendas e a distribuição etária e sexual presente. No entanto, foi possível observar, na área intervencionada, a tendência para a utilização de graus de combustão elevados, a aplicação da cremação exclusivamente a cadáveres e não a esqueletos e a forte presença de não adultos, a maioria com menos de um ano de vida (5/10). Este último facto, se se estendesse a toda a área funerária, poderia indicar uma alta mortalidade infantil na época, e surpreende pela conservação de restos de indivíduos muito jovens, face à fragilidade dos seus ossos.

Palavras-chave Análise antropológica; cremação; espólio osteológico e odontológico; rituais funerários.

\section{Introdução}

No âmbito do Programa de Modernização do Parque Escolar decorreram obras de requalificação da Escola Secundária Gabriel Pereira (ESGP), em Évora, que conduziram ao acompanhamento arqueológico desenvolvido pela Empresa de Arqueologia ArkeoHabilis. No decorrer do mesmo, foi colocado em evidência um contexto funerário romano (Figura 1), parcialmente escavado durante o mês de
It was possible to observe a high variability on the building and use of funeral structures, as for their typology and the post cremation process, common in roman burial areas in Hispania as in other places from the Roman Empire. No connection was found between the structure types, the offerings found at the polls and the age and sexual distribution. However, it was noticed on this place a tendency for high combustion degrees use, an exclusive cremation in cadavers not skeletons and a strong non adult presence most of which less than one year old (5/10). This last fact, if extended to all burial area, could indicate a high infant mortality at that time, though surprising for the conservation of very young individuals remains, considering their bones fragility.

Key words Paleodemographic analysis; cremation; osteological and odontological material; burial rituals.

Agosto de 2009, estando a intervenção antropológica sob a responsabilidade de uma das autoras (Teresa Matos Fernandes). A escola localiza-se junto ao Baluarte dos Apóstolos, a Norte/NE do núcleo urbano antigo da cidade de Évora, e está inserida no perímetro de protecção do conjunto "Fossos e Muralhas de Évora", classificado como Monumento Nacional e protegido pelo Decreto-Lei no 11733, DG 135 de 23 de Junho de 1926. As actuais instalações da Escola Secundária Gabriel 


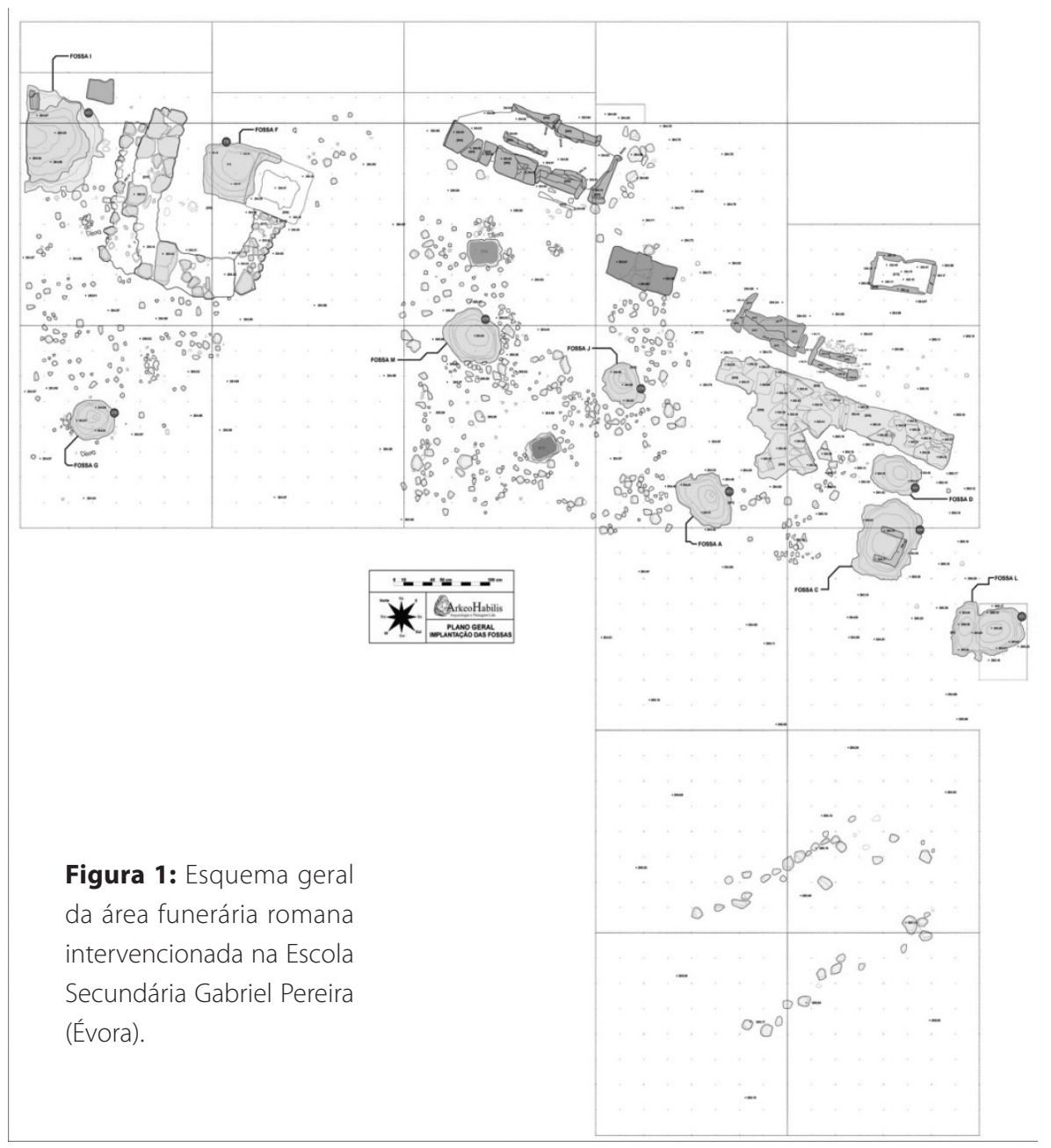

Pereira datam de 1970, não havendo dessa ou de outras datas informações sobre a história do local. Esta primeira intervenção arqueológica corresponde a aproximadamente 25,000 m², desenvolvendo-se, de forma mais ou menos alongada, no sentido NW/SE.

Neste trabalho são apresentados os resultados das investigações efectuadas ao material proveniente do interior das estruturas funerárias identificadas no local, sob a forma de covachos, urnas cerâmicas e sepulturas rectangulares, exemplificadas pelas figuras 2, 3 e 4, respectivamente. A necrópole está datada através, sobretudo, de numismas recolhidos na área, do 3. quartel do século I d.C. e o 2. quartel do século II d.C. (Gonçalves e Maia, 2010). 


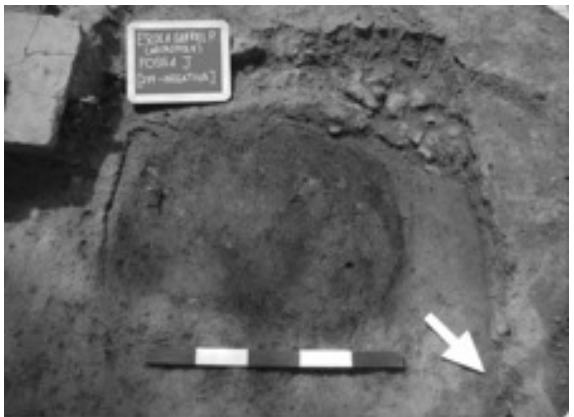

Figura 2: Fossa J, com o formato de covacho, intervencionada na área funerária romana (ESGP).

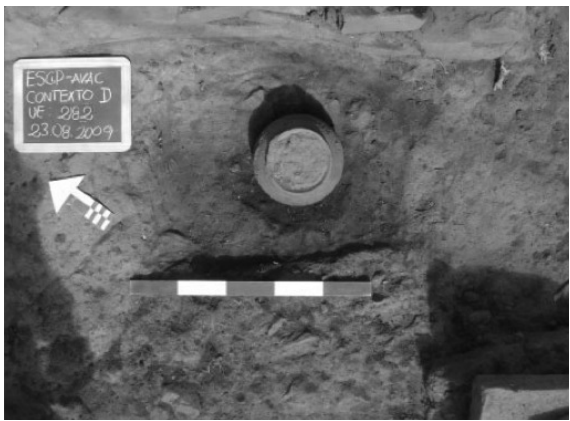

Figura 3: Contexto D, com urna de cremação no interior, levantada da área funerária romana (ESGP).

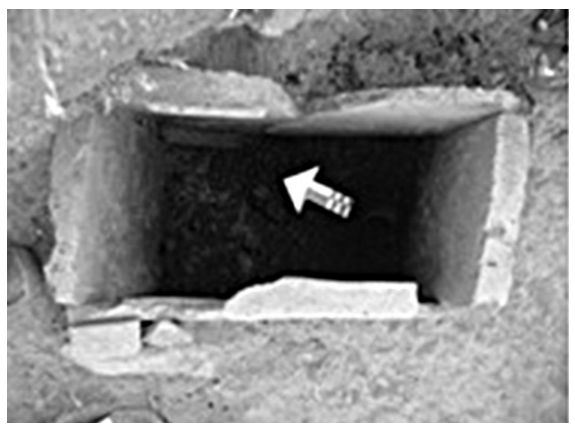

Figura 4: Estrutura B, delimitada por sepultura rectangular, identificada na área funerária romana (ESGP).
O material objecto de estudo é constituído pelo espólio osteológico e odontológico proveniente de 11 cremações e de uma inumação. Neste texto utilizar-se-á o vocábulo cremação por ser aquele que melhor traduz as ocorrências desta necrópole, uma vez que Ihe está implícito o acto de queimar o cadáver ou esqueleto, tornando-o mais abrangente do que o termo incineração que implica a redução a cinzas (Campillo, 2001).

A prática de cremações prevaleceu em várias sociedades humanas de diferentes regiões geográficas e em vários períodos da História da Humanidade (Krogman e İşcan, 1986). No período Romano, até aos séculos III a IV d.C., coexistiram as práticas funerárias de cremação e de inumação, com variação de importância de uma ou de outra em função do período ou, provavelmente, do contexto geográfico (Mesquida e Val, 1993; Polo Cerdá et al., 2009). Também em território português está documentada a coexistência das duas práticas funerárias (e.g. Fabião et al., 1998; Frade e Caetano, 1995).

Para os romanos o conjunto de rituais associados ao sepultamento, funus, baseava-se na concepção da sobrevivência da alma após a morte, era complexo e variável em função de parâmetros sociais e etários do defunto e da zona geográfica, por exemplo. Os enterramentos ocorriam nas necrópoles, ou "cidades dos mortos", que, até finais do período imperial, se localizavam obrigatoriamente fora do re- 
cinto simbólico da "cidade dos vivos", o pomerium (Rolo, 2010). Excepção a este critério constitui o facto de se encontrarem sepultamentos de alguns indivíduos infantis, maioritariamente neonatos, em ambiente doméstico (Crespo, 2008). Para este grupo etário não era apenas o local de enterramento que diferia em relação ao dos outros indivíduos da sua comunidade. Segundo autores como Hope (2007), os neonatos e os infantis aos quais não tivessem, à data da morte, irrompido os dentes seriam inumados e não incinerados.

De acordo com Hope (2007) e Boiça e Lopes (1999), de uma forma resumida e apesar de, como já referido, os rituais serem variáveis em função nomeadamente da categoria social, o funus compreendia três fases. Na primeira fase distinguiam-se três etapas. Na primeira realizavam-se os rituais que conduziriam à libertação da alma do defunto e que consistiam no último beijo, na lavagem e unção do corpo, na deposição do óbolo para Caronte e na exposição do corpo na casa, geralmente no átrio. A segunda etapa consistia na procissão que acompanhava o corpo até ao local de sepultamento. Aí iniciava-se a terceira etapa, que poderia corresponder à inumação ou à cremação.

A cremação implicava a colocação do corpo numa pira funerária de madeira, o rogus, cuja localização poderia ser sobre uma fossa onde o defunto era coloca- do, o bustum, constituindo uma deposição primária, ou numa estrutura para cremação, o ustrinum, a partir da qual e após recolha, em grau variável, de cinzas e fragmentos ósseos, se procedia ao seu depósito, secundário, em estrutura funerária de tipologia variável (urnas de cerâmica, de pedra, etc.). Junto ou no interior das estruturas funerárias eram habitualmente colocadas oferendas de que se destacam as lucernas, interpretadas como símbolos de luz.

A segunda fase do funus correspondia a um período de expiação por parte dos familiares e incluía um banquete fúnebre que poderia incluir manifestações, tais como a oferta de alimentos ou a deposição do espólio do banquete no local da sepultura.

A terceira fase visava aplacar o espírito do defunto e reiterar a separação entre o mundo dos vivos e o dos mortos. Era constituída por um variado conjunto de manifestações rituais que se estendiam ao longo do calendário, tais como a comemoração do dia de aniversário do defunto ou da data da sua morte.

A análise das cremações pode possuir um carácter arqueológico, metodológico ou ainda antropológico e forense (Krogman e Işscan, 1986), e apesar de frequentemente tais caracterizações estarem extremamente limitadas em consequência da fraca representatividade e do mau estado de conservação dos elementos esqueléticos presentes em cremações, 
muita informação pode ser extraída se os dados forem correctamente recolhidos e analisados (Ubelaker, 1989). De entre as informações passíveis de serem obtidas com vista à reconstituição dos gestos funerários destacam-se as seguintes:

- a condição aquando da cremação, isto é, se foi o cadáver ou o esqueleto o objecto da cremação (Ubelaker, 1989; Silva, 2007). O osso tem tendência a abrir fissuras (fracturas longitudinais, transversais encurvadas, transversais direitas e pátina), deformar, distorcer e encolher (Silva, 2007; Silva et al., 2007/2008; Byers, 2008) quando exposto ao calor, sendo o fenómeno de deformação quase exclusivamente evidenciado em cadáveres (Ubelaker, 1989; Silva, 2007; Silva et al., 2007/2008), tal como as fissuras transversais encurvadas em ossos longos (Herrman e Bennett, 1999). As fracturas longitudinais estão tendencialmente associadas a cremações após esqueletização do cadáver (Ubelaker, 1989; Silva, 2007; Silva et al., 2007/2008);

- o grau de combustão a que o corpo foi sujeito, ou seja, o intervalo de temperatura utilizado, nomeadamente através da cor resultante no vestígio ósseo, que segue um padrão previsível (Shipman et al., 1984; Krogman e İşcan, 1986; Ubelaker, 1989; Silva, 2007; Silva et al., 2007/2008; Byers, 2008), como apresentado na tabela 1;

- a posição ocupada pelo corpo no bustum, pela análise das zonas anatómicas mais afectadas pela acção do fogo (McKinley, 2000);

- a relação entre a localização da pira funerária e a deposição dos restos da cremação, ou seja, se o conjunto de cinzas e ossos constitui um depósito primário, com delimitação da estrutura funerária em torno dos mesmos no próprio local de cremação, ou secundário, com transporte e acondicionamento destes noutro local (Ubelaker, 1989; Corga et al., 2007; Silva, 2007; Silva et al., 2007/2008);

- a relação física e estratigráfica entre os ossos humanos cremados e/ou as suas cinzas e oferendas, quer de objectos quer de animais, que tenham sido feitas permitindo a interpretação da estrutura funerária (Mckinley, 2000).

$\mathrm{Na}$ interface entre a abordagem aos rituais funerários e a análise bioantropológica ao material osteológico e odontológico, com a reconstituição do perfil biológico do material cremado, está ainda o cálculo do número mínimo de indivíduos por sepultura (Andrews e Bello, 2006), que permite distinguir sepulturas 
Tabela 1. Intervalos de temperatura e respectivas colorações (adaptado de Shipman et al., 1984, por Silva, 2007).

\begin{tabular}{|c|l|}
\hline Temperatura & Alteração de Coloração \\
\hline $20-285^{\circ} \mathrm{C}$ & Branco pálido, amarelo claro e amarelo \\
\hline $285-525^{\circ} \mathrm{C}$ & Castanho avermelhado, castanho e cinzento escuro, cinzento escuro, amarelo avermelhado \\
\hline $525-645^{\circ} \mathrm{C}$ & Preto, com presença de azul intermédio e algum amarelo avermelhado \\
\hline $645-940^{\circ} \mathrm{C}$ & Predomínio do branco com presença de cinzento azulado e cinzento claro \\
\hline$>940^{\circ} \mathrm{C}$ & Branco com algum cinzento intermédio e amarelo avermelhado \\
\hline
\end{tabular}

individuais ou pôr a descoberto ossos de cremações múltiplas, o que ocorre quando a combustão é feita em simultâneo (Duday, 2006), ou de cremações colectivas, as quais revelam deposição numa única estrutura funerária de restos de cremações efectuadas em momentos distintos (Tranoy, 2000). É de referir que estas duas categorias podem ser bastante difíceis de distinguir (Mckinley, 2000).

É objectivo do presente trabalho o estudo das 11 cremações e da inumação postas a descoberto na Escola Secundária Gabriel Pereira, e que constitui a primeira investigação realizada em restos cremados provenientes de Évora, apesar da reconhecida importância que a cidade, Ebora Liberalitas Julia, teve em tempos imperiais, como o atestam alguns edifícios que chegaram aos nossos tempos, de que são exemplo o emblemático templo, de culto imperial e que ocupa posição cimeira na acrópole, as termas públicas patentes no actual edifício da Câmara Municipal, núcleo habitacional na Rua da Alcárcova de Cima, vários troços de muralha ou, entre outros, parte do Decumanus urbano que partiria da actual
Praça do Geraldo rumando ao templo, e que foi possível observar na sequência de uma intervenção arqueológica na Rua Vasco da Gama (Mantas, 2010).

\section{Material e métodos}

Durante a escavação foram detectadas 15 estruturas cuja tipologia e utilização se encontram na figura 5. As estruturas funerárias, após documentação gráfica (desenho à escala 1:10, registo de coordenadas e altimetrias e fotografia), foram referenciadas e os respectivos conteúdos foram levantados em bloco para posterior escavação em laboratório de forma a diminuir o tempo de intervenção em campo e minimizar o impacto na obra.

A escavação em laboratório', efectuada pelas autoras, visou a identificação dos fragmentos encontrados, os quais foram agrupados por região anatómica (i.e. crânio, tronco, membros e indeter-

\footnotetext{
1 Para além de pincéis e ferramentas leves recorreu-se à água para libertação do material antropológico da terra e cinzas em que estava embalado.
} 
Figura 5: Tipologia das estruturas funerárias intervencionadas e registo do tipo de vestígio biológico humano.

\section{Estruturas Funerárias}

190

minados) e lateralidade com o objectivo de identificar eventuais repetições de peças ósseas no interior de cada estrutura funerária que conduzisse ao cálculo do número de indivíduos. De seguida analisaram-se os fragmentos ósseos ao nível da cor (considerando o método de Shipman et al., 1984), do encolhimento (presença/ausência), da deformação (presença/ausência), do grau de fragmentação (anotando-se a menor e maior dimensão dos fragmentos, sendo que para efectuar as medições necessárias foi utilizada uma craveira digital $(0,01 \mathrm{~mm}))$, do tipo de fracturas (descritas por Herrmann e Bennett, 1999) e da presença de patologias. Os restos ósseos de cada estrutura funerária foram pesados de modo a avaliar-se a representatividade por região anatómica considerada. As pesagens fo- ram feitas recorrendo-se a uma balança digital, registando-se o valor à centésima de grama.

No caso das duas urnas cerâmicas que chegaram a laboratório², para além dos procedimentos acima referidos, foram radiografadas ${ }^{3}$ a $95 \mathrm{KV}$ e $30 \mathrm{mAs}$ e a 100 KV e 40 mAs (Figura 6) de modo a tentar observar-se o seu conteúdo, nomeadamente presença de espólio arqueológico evitando assim danos durante o procedimento de remoção de terra.

\footnotetext{
2 A terceira urna cerâmica encontrava-se já fragmentada em campo, apenas tendo sido enviado para laboratório o seu conteúdo.

3 As radiografias foram efectuadas pelo Prof. Doutor José Potes no Serviço de Imagiologia do Hospital Veterinário da Universidade de Évora, a quem se agradece a colaboração.
} 


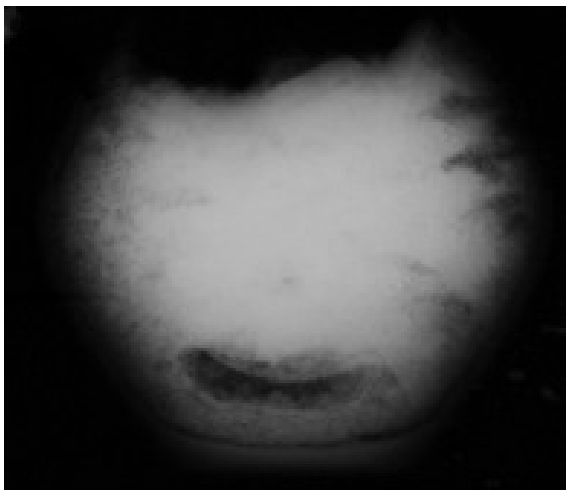

Figura 6. Radiografia da urna D (95KV, 30mAs).

Em todos os casos estudados foi também anotado o espólio associado (Figura 7).

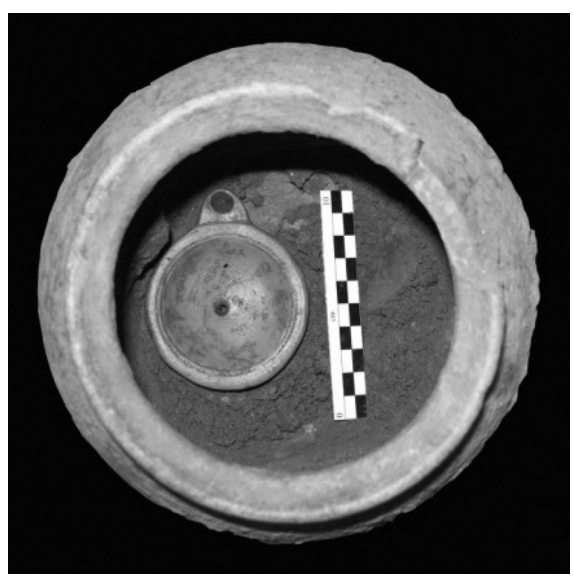

Figura 7. Fotografia de laboratório de ESGP-AVAC fossa D, urna de cerâmica contendo no seu interior uma lucerna.

Seguidamente tentou proceder-se à diagnose sexual e etária dos indivíduos estudados, diagnoses que se encontravam à partida comprometidas pelas pe- ças disponíveis para análise. Para a identificação da idade à morte distinguiram-se inicialmente os não adultos dos adultos pela fusão das epífises às diáfises, pela presença de dentição decídua e pela dimensão dos ossos identificados. Feita a distinção, atribuiu-se um intervalo etário aos não-adultos, seguindo os métodos propostos, em 2000, por Scheuer e Black, para a morfologia e fusão de elementos ósseos, Moorrees et al. (1963) modificado por Smith, em 1991, Liversidge e colegas em 1998 (in Scheuer e Black, 2000), ou ainda a metodologia de Ubelaker (1989) para a formação e erupção dentária. Para os adultos consideraram-se 3 classes etárias: adultos jovens (dos 21 aos 30 anos), adultos, e adultos idosos. A inclusão na primeira destas classes resultou da aplicação das propostas de Scheuer e Black (2000) para elementos ósseos com fusões incompletas, enquanto que para as outras classes se tiveram em conta o desgaste dentário (Escala de Smith, 1984 in Hillson, 1996), a presença/ausência de osteoartroses e o encerramento das suturas cranianas (Masset, 1982). Estes critérios foram meramente indicativos sobre se o indivíduo em análise pertenceria ou não à classe dos jovens ou dos idosos. A diagnose sexual dos adultos baseou-se no método proposto por Norén e colaboradores (2005), dado o fraco estado de conservação dos elementos ósseos mais dimórficos do esqueleto, isto é, o coxal e o crânio, impossibilitando a utilização da metodologia clássica. 
Tabela 2. Síntese dos perfis biológicos obtidos ( $M$ - Masculino; F - Feminino).

\begin{tabular}{|c|c|c|c|c|c|c|}
\hline $\begin{array}{l}\text { Estruturas } \\
\text { funerárias }\end{array}$ & Tipologia & $\begin{array}{c}\text { Método Diagnose } \\
\text { Sexual }\end{array}$ & Sexo & Método Estimação Idade & Idade & Patologias \\
\hline Estrutura B & Sepultura rectangular & Norén et al., 2005 & $M$ & Smith, 1994 & Adulto & - \\
\hline Estrutura B2 & Sepultura rectangular & Norén et al., 2005 & M & Scheuer e Black, 2000 & Adulto Jovem & $\begin{array}{l}\text { Periostite ligeira } \\
\text { activa num fémur }\end{array}$ \\
\hline Estrutura E & $\begin{array}{c}\begin{array}{c}\text { Sepultura rectangular } \\
\text { Inumação }\end{array} \\
\end{array}$ & - & - & \begin{tabular}{|c|} 
Moorrees et al., 1963 adaptado \\
Smith, 1991 in Scheuer e Black, 2000
\end{tabular} & 2 a 6 meses & - \\
\hline Fossa $\mathrm{A}$ & Urna de cremação & Norén et al., 2005 & $\mathrm{~F}$ & Scheuer e Black, 2000 & Adulto & $\begin{array}{c}\text { Periostite ligeira } \\
\text { numa ulna }\end{array}$ \\
\hline Fossa C & Urna de cremação & - & - & Scheuer e Black, 2000 & 18 a 20 anos & - \\
\hline Fossa D & Urna de cremação & - & - & $\begin{array}{l}\text { Liversidge et al., } 1998 \\
\text { in Scheuer e Black, } 2000\end{array}$ & 0 a 4 meses & - \\
\hline Fossa $\mathrm{E}$ & Covacho & - & - & $\begin{array}{l}\text { Liversidge et al., } 1998 \\
\text { in Scheuer e Black, } 2000\end{array}$ & 3 a 7 meses & - \\
\hline Fossa F & Covacho & - & - & - & - & - \\
\hline Fossa I & Covacho & - & - & - & - & - \\
\hline Fossa J & Covacho & - & - & Scheuer e Black, 2000 & o a 12 meses & - \\
\hline Fossa L & Covacho & - & - & Scheuer e Black, 2000 & Adulto & - \\
\hline Fossa M & Covacho & - & - & $\begin{array}{l}\text { Liversidge et al., } 1998 \\
\text { in Scheuer e Black, } 2000\end{array}$ & 8 a 14 meses & - \\
\hline
\end{tabular}

Finalmente, foi pesquisada a presença/ausência de patologias através de eventuais lesões deixadas no tecido ósseo e odontológico.

Para as urnas cerâmicas foi ainda feito o registo fotográfico das várias fases da sua escavação bem como do espólio encontrado in situ no seu interior. A escavação da estrutura de inumação foi igualmente fotografada, tal como alguns fragmentos provenientes das restantes cremações.

\section{Resultados e discussão}

As estruturas funerárias intervencionadas na Escola Secundária Gabriel Pereira, em Évora, e que continham espólio biológico humano, estão listadas na tabela 2 onde também se faz referência à sua tipologia, respectivos conteúdos votivos e biológicos (com informação sobre perfis biológicos e patologias).

Das 15 estruturas encontradas, 14 estavam associadas a rituais funerários que envolviam a cremação (3 das quais atribuídas ao tipo de rito por evidências não osteológicas, tendo ficado as restantes 11 disponíveis para análise antropológica) e apenas uma continha uma inumação (Figura 8).

A investigação laboratorial dos parâmetros biológicos foi feita, conjuntamente pelas autoras, ao espólio osteológico e odontológico proveniente de 12 estruturas funerárias, pois nas outras 3 não existiam vestígios passíveis de análise. Em todos os casos analisados as estruturas funerárias eram individuais dado que não se observaram repetições de estruturas anatómicas nem se detectaram incompatibilidades quanto ao sexo ou à idade 

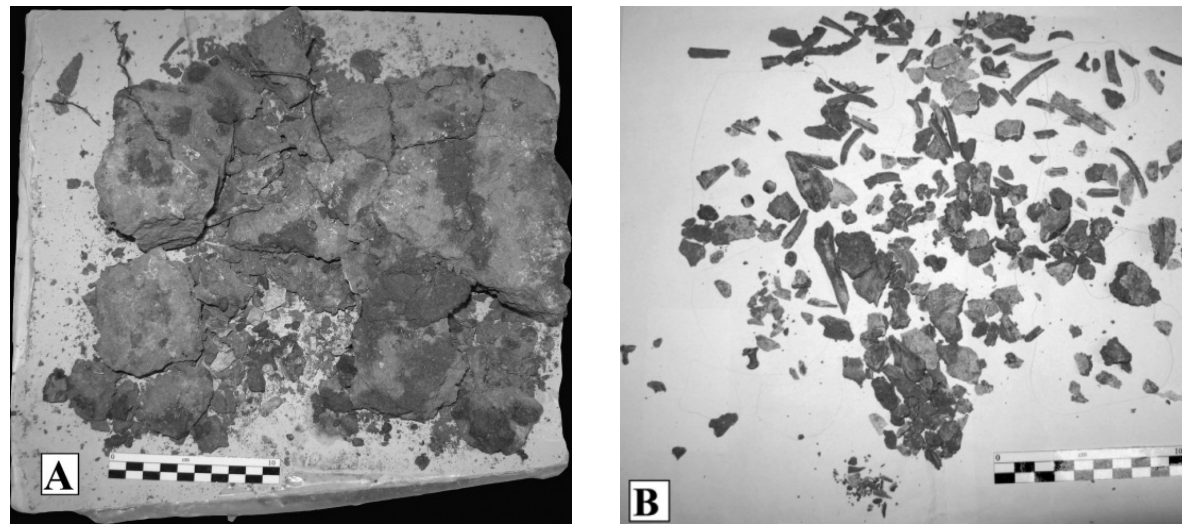

Figura 8. Fotografia de laboratório de ESGP-AVAC estrutura E, inumação de um não adulto $(0 \mathrm{a}$ 4 meses). A) Antes da intervenção em laboratório B) Fragmentos ósseos recolhidos.

à morte. Foi possível atribuir uma classe etária a 83,3\% (10/12) dos indivíduos e o sexo conseguiu-se determinar em $75 \%$ (3/4) dos adultos.

De entre os indivíduos com idade atribuída, o número de não-adultos (6/10) é superior ao número de adultos (4/10), sendo de ressaltar o facto dos indivíduos não adultos se situarem quase todos abaixo de um ano de idade. Estes resultados podem estar enviesados dado apenas uma zona da necrópole ter sido escavada e da eventual possibilidade de seccionamento dos padrões funerários da área e/ou distribuição desigual dos indivíduos em termos de caracteres demográficos ou outros. No caso desta forte presença estar dissociada de qualquer estruturação do espaço funerário segundo faixas etárias, revelará quer uma forte mortalidade infantil, quer um aparente desvio em relação às práticas funerárias romanas já referidas, segundo as quais as crianças com a dentição não erupcionada não deveriam ser considerados como membros da sua sociedade e, como tal, deveriam ser objecto de práticas funerárias distintas quer em relação ao ritual funerário, quer quanto ao próprio local de depósito (Hope, 2007). Contudo conhecem-se algumas necrópoles romanas que revelaram cremações de indivíduos muito jovens, como é o caso da necrópole da Via XVII, em Braga (Braga, 2010), ou as referenciadas por Hope (2007) para território inglês.

A fraca incidência de patologias detectada pode não traduzir a realidade do estado de saúde da população em resultado de vários factores entre os quais se destacam a representatividade e o estado de conservação dos elemen- 
Tabela 3. Oferendas encontradas em cada tipo de estrutura funerária, associada às diferentes faixas etárias e ao sexo diagnosticado.

\begin{tabular}{|c|c|c|c|c|}
\hline $\begin{array}{l}\text { Estruturas } \\
\text { funerárias }\end{array}$ & Tipologia & Espólio arqueológico & Sexo & Idade \\
\hline Estrutura B & Sepultura rectangular (tegullae) & Lucerna & Masculino & Adulto \\
\hline Estrutura B2 & $\begin{array}{c}\text { Sepultura rectangular (tegullae } \\
\text { e tijolos) - bustum }\end{array}$ & $\begin{array}{l}\text { Cabeça de alfinete em metal (elemento de } \\
\text { vestuário); fragmento de vidro }\end{array}$ & Masculino & Adulto \\
\hline Estrutura $\mathrm{E}$ & $\begin{array}{l}\text { Sepultura rectangular (tijolos) - } \\
\text { Inumação }\end{array}$ & - & Indeterminado & $<1$ ano \\
\hline Fossa A & Urna de cremação fragmentada & $\begin{array}{l}\text { Fragmentos de cerâmica; cabo metálico de } \\
\text { objecto não identificado; gancho de cabelo } \\
\text { metálico; fragmento de vidro; cadinho }\end{array}$ & Feminino & Adulto \\
\hline Fossa C & Urna de cremação & $\begin{array}{l}\text { Lacrimário; Lucerna; gancho de cabelo; fauna } \\
\text { (peixe); fragmento de vidro }\end{array}$ & Indeterminado & Adulto \\
\hline Fossa D & Urna de cremação & Lucerna & Indeterminado & $<1$ ano \\
\hline Fossa $\mathrm{E}$ & Covacho & Lucerna; contas de vidro (2); cossoiro; metal & Indeterminado & $<1$ ano \\
\hline Fossa F & Covacho & 3 frag. lucerna, 1 frag. ânfora, vários frag. vidro & Indeterminado & Indeterminada \\
\hline Fossa I & Covacho & $\begin{array}{c}\text { Contas em vidro; } 8 \text { fragmentos de lucerna; } \\
\text { ungentário? }\end{array}$ & Indeterminado & Indeterminada \\
\hline Fossa J & Covacho & Conta em pedra & Indeterminado & $<1$ ano \\
\hline Fossa L & Covacho & $\begin{array}{l}\text { Fauna (ave e mamífero); lucerna; fragmentos de } \\
\text { vidro; alfinete em osso }\end{array}$ & Indeterminado & Adulto \\
\hline Fossa M & Covacho & Fragmentos de vidro & Indeterminado & $<1$ ano \\
\hline
\end{tabular}

tos ósseos, para além das limitações inerentes à Paleopatologia, que resultam de apenas algumas patologias deixarem marcas observáveis nos tecidos esqueléticos, de que mesmo patologias passíveis de provocarem lesões poderem não o fazer em situações agudas, e de as lesões não serem, na sua maioria, patognomónicas.

Após a obtenção do perfil biológico dos indivíduos, nomeadamente, grupo etário e sexo, tentou-se encontrar relações entre estes parâmetros e a tipologia da estrutura funerária, o tipo de oferenda e, por fim, com o grau de combustão.

A tabela 3 apresenta a distribuição do tipo de oferendas pelos grupos etários e sexuais, que foram possíveis de estabelecer, e nos 3 tipos de estruturas funerárias.
Nesta tabela está patente a inexistência de relação entre o tipo de estrutura funerária e o sexo ou a idade. O tipo de oferendas era variado e aparentemente quase aleatória a sua associação ao grupo sexual ou etário. Foram recuperados vários tipos de oferta: lucernas, lacrimário, alfinetes de cabelo em osso, cossoiro, cadinho, contas em vidro, conta em pedra e fauna. Foi possível detectar que, ao contrário de outras necrópoles, como é o caso da Quinta da Torrinha, no Monte da Caparica (Assis e Barbosa, 2008), apenas as crianças mais jovens não possuíam elementos de adorno corporal. Estas crianças também não estavam acompanhadas de elementos de vestuário. As peças passíveis de serem, a priori, associadas a activi- 
dades profissionais (cossoiro e cadinho) também estavam presentes em grupos etários sem actividade profissional (como é o caso do cossoiro presente na Fossa $\mathrm{E}$ e onde se identificaram os vestígios de uma criança com uma idade à morte inferior a um ano) ou a grupos sexuais que tradicionalmente não as desempenhariam (cadinho em sepultura feminina, na Fossa A).

A presença de fauna (em 2 das 12 estruturas funerárias) foi interpretada como oferenda, pois era habitual a existência, já referida, de um banquete fúnebre e, de acordo com comunicação pessoal do Dr. Carlos Pimenta, os ossos de peixe detectados na Fossa C apresentavam sinais de terem sido cremados. O mesmo investigador identificou os ossos de uma ave, encontrados na Fossa L, como sendo possivelmente uma abetarda ou sisão, e acompanhados de ossos de um mamífero não identificado.

As lucernas constituíam, como habitualmente, o mobiliário votivo mais comum, estando documentadas em 6 das 12 estruturas postas a descoberto na intervenção arqueológica.

Para além destas oferendas foram ainda registados vários fragmentos de vidro e de metal não identificados, bem como pregos em duas das estruturas, os quais podem provir da zona da pira e terem sido recolhidos juntamente com as cinzas e espólio osteológico. A presença de pregos noutras áreas funerárias romanas tem sido interpretada como indicadora da presença de caixões ou padiolas para o transporte do defunto (Braga, 2010).

Para aceder ao grau de combustão interpretaram-se as distribuições por tipo de estrutura e por classe etária dos seguintes parâmetros pesquisados no espólio osteológico e odontológico: alteração de cor, grau de fragmentação, tipo de fracturas, deformação e peso dos fragmentos (Figura 9).

Os resultados desta análise às alterações provocadas pelo fogo no material osteológico e aos pesos constam na tabela 4. A análise das alterações de cor revelou resultados muito díspares entre os materiais provenientes das várias estruturas funerárias, bem como entre os vários ossos da mesma estrutura. Estes resultados podem reflectir uma vasta amplitude térmica associada às cremações desta necrópole, com predomínio de temperaturas superiores aos $645^{\circ} \mathrm{C}$ (Shipman et al., 1984; Krogman e Iş̧can, 1986; Ubelaker, 1989; Silva, 2007; Silva et al., 2007/2008; Byers, 2008), e/ou outros factores, como sejam diferentes tempos de exposição ao calor, diferentes recepções de oxigénio, diferente investimento por parte do cremador (Silva, 2007: 42), ou, ainda, variáveis tafonómicas (Nicholson, 1993). O grau de fragmentação, ou seja, a dimensão dos fragmentos ósseos presentes, era semelhante nos vários tipos de estruturas funerárias. Vários autores citados por Silva (2007) consideram que este 

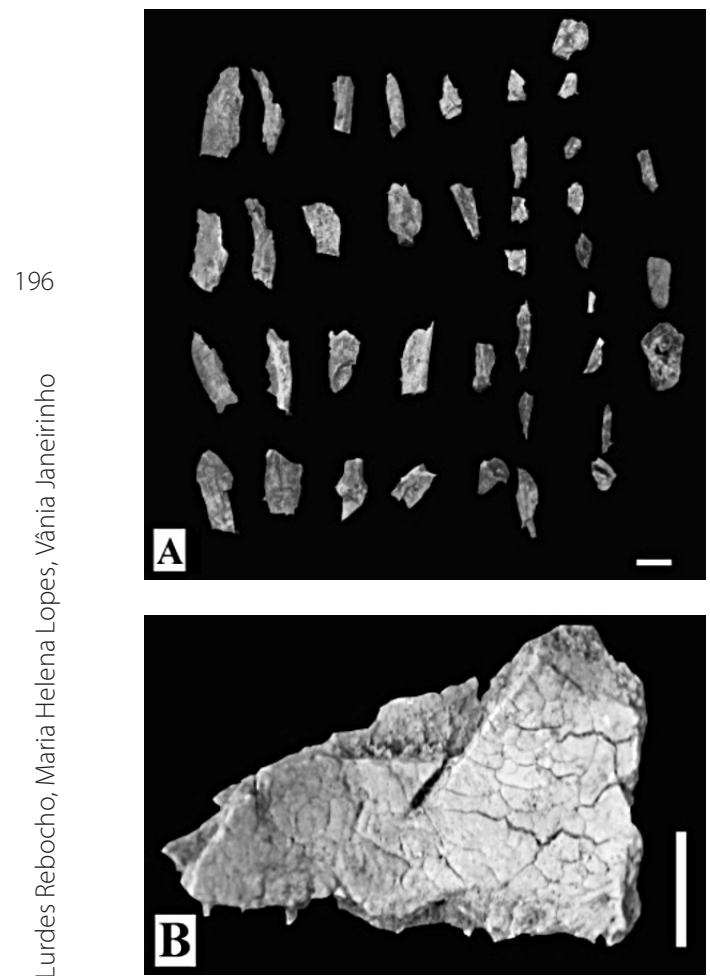
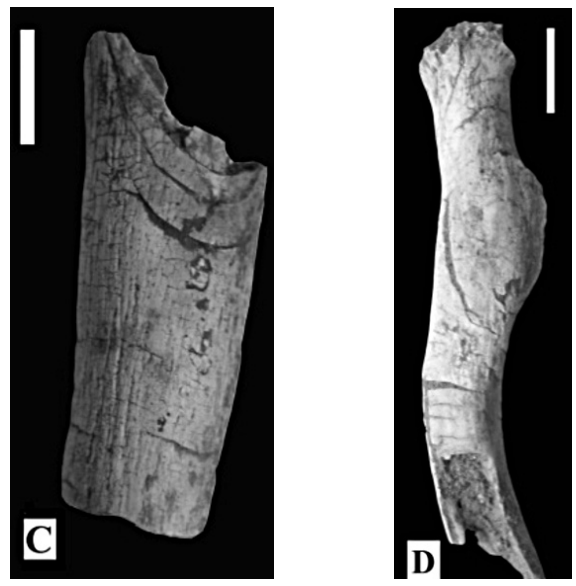

Figura 9. A. Grau de fragmentação (ESGP-AVAC fossa J). B. Padrão de fracturas - patina - num fragmento de crânio (ESGP-AVAC fossa C). C. Padrão de fracturas transversais encurvadas num fragmento de diáfise de osso longo (ESGP-AVAC fossa A). D. Deformação num fragmento de rádio (ESGP-AVAC fossa C). Escala $1 \mathrm{~cm}$.

Tabela 4. Síntese das alterações provocadas pelo fogo no material osteológico analisado, por tipo de estrutura funerária. Alteração de cor, grau de fragmentação, tipo de fracturas e peso dos fragmentos, por grupo etário. (A - Adulto; NA - Não adulto; I - Indeterminado; * Inumação sem alterações provocadas pelo fogo).

\begin{tabular}{|c|c|c|c|c|c|c|c|c|c|c|c|c|}
\hline \multirow{2}{*}{$\begin{array}{c}\text { Tipo de } \\
\text { Estrutura } \\
(\mathrm{n} / \mathrm{N})\end{array}$} & \multicolumn{3}{|c|}{ Alteração de cor } & \multicolumn{3}{|c|}{\begin{tabular}{|} 
Grau de fragmentação \\
(maior a menor fragmento, em mm)
\end{tabular}} & \multicolumn{3}{|c|}{ Tipo de fractura } & \multicolumn{3}{|c|}{$\begin{array}{l}\text { Peso médio por } \\
\text { grupo etário (g) }\end{array}$} \\
\hline & $A(n / N)$ & $\mathrm{NA}(\mathrm{n} / \mathrm{N})$ & $\mathrm{I}(\mathrm{n} / \mathrm{N})$ & $A(n / N)$ & $\mathrm{NA}(\mathrm{n} / \mathrm{N})$ & $\mathrm{I}(\mathrm{n} / \mathrm{N})$ & $\mathrm{A}(\mathrm{n} / \mathrm{N})$ & $\mathrm{NA}(\mathrm{n} / \mathrm{N})$ & $\mathrm{I}(\mathrm{n} / \mathrm{N})$ & $A(n / N)$ & $\mathrm{NA}(\mathrm{n} / \mathrm{N})$ & $\mathrm{I}(\mathrm{n} / \mathrm{N})$ \\
\hline $\begin{array}{c}\text { Covachos } \\
(6 / 12)\end{array}$ & $\begin{array}{l}\text { Branco } \\
(1 / 12))\end{array}$ & $\begin{array}{c}\text { Preto; } \\
\text { amarelo; } \\
\text { branco } \\
(3 / 12)\end{array}$ & $\begin{array}{c}\text { Preto; } \\
\text { azul; } \\
\text { cinzento; } \\
\text { branco } \\
(2 / 12)\end{array}$ & $\begin{array}{l}6,12 \mathrm{a} \\
50,04 \\
(1 / 12)\end{array}$ & $\begin{array}{l}3,41 \mathrm{a} \\
32,54 \\
(3 / 12)\end{array}$ & $\begin{array}{l}4,03 \mathrm{a} \\
64,40 \\
(2 / 12)\end{array}$ & $\begin{array}{c}\text { Transversais } \\
\text { encurvadas; } \\
\text { longitudinais; } \\
\text { pátina } \\
(1 / 12))\end{array}$ & \begin{tabular}{|c|} 
Transversais \\
encurvadas \\
$(3 / 12)$
\end{tabular} & $\begin{array}{c}\text { Transversais } \\
\text { encurvadas } \\
\text { pátina } \\
(2 / 12)\end{array}$ & $\begin{array}{l}816,09 \\
(1 / 12)\end{array}$ & $\begin{array}{c}17,17 \\
(3 / 12)\end{array}$ & $\begin{array}{l}79,53 \\
(2 / 12)\end{array}$ \\
\hline $\begin{array}{c}\text { Urnas de } \\
\text { cremação } \\
(3 / 12)\end{array}$ & $\begin{array}{c}\text { Castanho; } \\
\text { cinzento } \\
\text { escuro; } \\
\text { branco } \\
(2 / 12)\end{array}$ & $\begin{array}{l}\text { Cinzento } \\
\text { escuro; } \\
\text { cinzento } \\
\text { claro; } \\
\text { branco } \\
(1 / 12)\end{array}$ & - & $\begin{array}{l}5,42 a \\
102,09 \\
(2 / 12)\end{array}$ & $\begin{array}{l}1,96 \mathrm{a} \\
24,21 \\
(1 / 12)\end{array}$ & - & \begin{tabular}{|c|} 
Transversais \\
encurvadas e \\
direitas; \\
longitudinais \\
$(2 / 12)$
\end{tabular} & $\begin{array}{c}\text { Transversais } \\
\text { encurvadas; } \\
\text { longitudinais; } \\
\text { pátina } \\
(1 / 12))\end{array}$ & - & $\begin{array}{l}542,62 \\
(2 / 12)\end{array}$ & $\begin{array}{l}25,63 \\
(1 / 12)\end{array}$ & - \\
\hline $\begin{array}{c}\text { Sepulturas } \\
\text { rectangulares } \\
(3 / 12)\end{array}$ & \begin{tabular}{|c|} 
Cinzento \\
claro; \\
cinzento \\
azulado; \\
branco \\
$(2 / 12)$
\end{tabular} & * & - & $\begin{array}{l}4,87 a \\
51,44 \\
(2 / 12)\end{array}$ & * & - & \begin{tabular}{|c|} 
Transversais \\
encurvadas; \\
longitudinais; \\
pátina \\
$(2 / 12))$
\end{tabular} & * & - & $\begin{array}{l}140,77 \\
(2 / 12)\end{array}$ & $\begin{array}{c}5,54 \\
(1 / 12)\end{array}$ & - \\
\hline
\end{tabular}


parâmetro depende de aspectos tão diversos como os associados à combustão (temperatura, duração, madeira utilizada, proximidade em relação à fonte de calor, entre outros), aos gestos funerários associados ao processo de enterramento ou ainda a questões metodológicas que se prendem com a escavação. As fracturas patentes nos restos analisados eram também variadas. Assim, registaram-se fracturas transversais encurvadas e direitas, longitudinais e de pátina nos restos recolhidos de todo o tipo de estrutura funerária, sendo que apenas os adultos possuíam os quatro tipos de fracturas.

Quanto às deformações ósseas resultantes da combustão deve referir-se que estavam patentes em 45,5\% dos indivíduos, sendo o crânio a zona anatómica com maior frequência de deformações. Este último dado é possivelmente explicado pela reduzida densidade óssea dos ossos cranianos (oferecendo menor resistência ao calor) e pela sua forte represen- tatividade na amostra, facto apresentado e discutido de seguida.

Uma abordagem mais detalhada ao peso nos restos cremados está patente na tabela 5.

A análise desta última tabela indica 197 que, em termos proporcionais, o crânio foi a zona anatómica em que se obteve maior peso, já o tronco (costelas, vértebras e coxais) foi a zona com menor peso. Estes resultados levam, para os depósitos secundários das cremações, a duas possíveis interpretações: o cadáver era depositado sobre a pira de tal forma que a zona do tronco era a que estava mais próxima da fonte de calor, ou, aquando da recolha dos restos da cremação, havia um maior cuidado com a recolha de fragmentos do crânio. Contudo, deve-se ter presente que, em cremações, os ossos cranianos são mais facilmente identificáveis do que os ossos dos membros e consequentemente não englobarão a classe "Ossos não identificados" da tabela

Tabela 5. Síntese dos pesos (g) do material osteológico recolhido nas várias estruturas funerárias por zona anatómica.

\begin{tabular}{|c|c|c|c|c|c|c|c|}
\hline $\begin{array}{l}\text { Estruturas } \\
\text { funerárias }\end{array}$ & $\begin{array}{c}\text { Crânio e/ou } \\
\text { dentição }\end{array}$ & Tronco & \begin{tabular}{|c|} 
Membros \\
superiores
\end{tabular} & $\begin{array}{l}\text { Membros } \\
\text { inferiores }\end{array}$ & $\begin{array}{c}\text { Membros + ossos } \\
\text { longos não identificados }\end{array}$ & $\begin{array}{c}\text { Ossos não } \\
\text { identificados }\end{array}$ & TOTAL \\
\hline Estrutura B & 12,237 & 0,267 & - & 1,751 & 59,625 & - & 73,880 \\
\hline Estrutura B2 & 45,663 & 7,214 & 6,663 & 23,154 & 32,450 & 92,515 & 207,659 \\
\hline Estrutura E & 0,393 & - & - & - & 2,333 & 2,809 & 5,535 \\
\hline Fossa A & 65,459 & 36,610 & 15,587 & 74,820 & 178,626 & 30,385 & 401,487 \\
\hline Fossa C & 85,500 & 52,008 & 39,219 & 90,708 & 317,790 & 98,529 & 683,754 \\
\hline Fossa D & 11,888 & 1,066 & - & - & 6,046 & 6,631 & 25,631 \\
\hline Fossa $\mathrm{E}$ & 0,393 & - & - & - & 2,333 & 2,809 & 5,535 \\
\hline Fossa F & 14,719 & - & - & - & 7,423 & 97,645 & 119,787 \\
\hline Fossa I & 4,865 & - & - & - & 34,416 & - & 39,281 \\
\hline Fossa J & 6,061 & 1,316 & - & - & 36,002 & - & 43,379 \\
\hline Fossa L & 136,057 & 42,472 & 9,217 & 5,681 & 339,840 & 282,823 & 816,090 \\
\hline Fossa M & 0,566 & - & - & - & - & 2,021 & 2,587 \\
\hline MÉDIA & 31,983 & 20,136 & 17,672 & 39,223 & 92,444 & 68,463 & 202,050 \\
\hline
\end{tabular}


5. Este último dado representa a confirmação à regra, definida por Mays (1998), que salientou a facilidade de identificação de determinadas peças ósseas, por especificidades morfológicas e estruturais das mesmas. Deste modo, a identificação determina inevitavelmente o perfil de representatividade. Quanto menos precisa for a identificação, mais distanciados da realidade serão os valores da representatividade óssea. A identificação e, consequentemente, a representatividade dependem, de igual modo, da preservação óssea, a qual, por sua vez, é fruto da interacção de factores extrínsecos e intrínsecos ao próprio osso (Silva et al., 2007/2008). A reduzida preservação de elementos do tronco, como as costelas e vértebras, pode ser justificada recorrendo ao argumento da densidade óssea, baixa nestes ossos (Boddington, 1987; Nawrocki, 1995) - factor intrínseco - ou à proximidade e tempo de exposição ao fogo, como mencionado acima - factor extrínseco.

\section{Conclusões}

Numa tentativa de síntese dos resultados atrás apresentados interessa salientar em primeiro lugar:

- a habitual diversidade tipológica das estruturas funerárias roma- nas está também presente nesta necrópole de Évora onde se detectaram 7 simples covachos escavados no solo, contendo cinzas, carvões e restos esqueléticos, e delimitados por círculos de pedras, 3 covachos ou fossas onde se depositaram urnas cerâmicas que albergavam as cinzas, os restos esqueléticos e alguns carvões resultantes das cremações, e $\mathbf{5}$ estruturas de planta rectangular com paredes e cobertura constituídos por materiais cerâmicos de construção;

- a existência de diferentes rituais funerários: uma inumação (Estrutura E) e 14 depósitos de cremação. A análise destes últimos revela que as cremações foram efectuadas de distintas formas, tendo sido identificado pelo menos um caso de bustum, ou cremação no local da sepultura (Estrutura B2), e vários casos de deposição secundária dos resíduos de cremações efectuadas noutro local que não o das sepulturas, provavelmente num ustrinum que não foi possível detectar (Fossas A, C, D, E, F, G, I, J, L e M);

- as diferentes temperaturas de combustão e/ou de tempo de combustão identificadas a partir das variadas colorações que o espólio antropológico apresentava (de 
branco pálido ou amarelado a branco com cinzento intermédio) e também da deformação óssea patente em alguns fragmentos e ausente noutros. Contudo, pode afirmar-se serem mais frequentes as elevadas temperaturas de combustão;

- a diversificação também patente no tipo de oferendas, com uma das estruturas (fossa C), que albergava uma adolescente tardia, a conter um lacrimário/unguentário, está de acordo com os resultados obtidos noutras necrópoles romanas em território português, como é o caso, entre muitas outras, da Rouca, Alandroal (Rolo, 2010).

Comum a todo o espólio osteológico e odontológico é a presença de fracturas e deformações que permitem pensar que, em todos os casos, as cremações foram efectuadas aos cadáveres e não aos esqueletos.

A associação entre ritual funerário, tipologia da estrutura por um lado e sexo e idade por outro é menos clara. De facto, não havia nenhuma associação preferencial entre a tipologia da estrutura funerária e os grupos sexuais e etários (não adulto/ adulto), nem entre estes parâmetros biológicos e a presença de oferendas.

Quanto aos dados da investigação bioantropológica é de salientar quer a elevada presença de indivíduos não adul- tos (6 em 10 daqueles a que foi possível determinar a idade à morte), quer o facto de quase todos terem menos de um ano de idade. A dimensão da amostra e a área intervencionada durante a escavação não permitem a caracterização demográfica da amostra analisada, contudo estas indicações vão ao encontro da expectativa de uma elevada mortalidade perinatal para este período cronológico.

O facto de ter sido possível retirar um variado leque de conclusões ilustra bem a importância quer do estudo laboratorial de material osteológico e odontológico, mesmo que muito fragmentado, quer da metodologia de escavação. No presente caso, as informações recolhidas tornam-se ainda mais relevantes, visto tratar-se do primeiro trabalho feito com base em deposições de cremações de uma necrópole romana da cidade de Évora.

\section{Referências bibliográficas}

Andrews, P.; Bello, S. 2006. Pattern in human burial practice. In: Gowland, R.; Knusel, C. (eds.). Social archaeology of funeral remains. Oxford, Oxbow Books: 14-29.

Assis, S.; Barbosa, R. 2008. A Necrópole Romana da Quinta da Torrinha/Quinta de Santo António. Monte da Caparica (III-V d.C.). Incursão ao universo funerário, paleodemográfico e morfométrico. Al-Madam online, 16 (2a Série), V: 1-12. 
Boddington, A. 1987. Chaos, disturbance and decay in an Anglo-saxon cemetery. In: Boddington, A.; Garland, A.; Janaway, R. (eds.) Death, decay and reconstruction: approaches to archaeology and forensic

Boiça, J.; Lopes, V. (eds.) 1999. Museu de Mértola: a Necrópole e a ermida da achada de S. Sebastião. Mértola, Escola Bento de Jesus Caraça e Campo Arqueológico de Mértola.

Braga, C. 2010. Rituais funerários em Bracara Augusta: o novo núcleo de necrópole da Via XVII. Dissertação de Mestrado, Universidade do Minho.

Byers, S. 2008. Introduction to forensic anthropology. Boston, Pearson Education.

Campillo, D. 2001. Introducción a la Paleopatología. Barcelona, Bellaterra.

Corga, M.; Ferreira, M.; Neves, M.; Almeida, M.; Gonçalves, F. 2007. Uma sepultura de incineração no Monte da Vinha 2 (S. Manços, Évora). Al-madan online, adenda electrónica, 15: 6 [Acedido em 0802-2010].

Crespo, T. 2008. Los enterramientos infantiles en contextos domésticos de la Cuenca Alta/Media del Ebro: a propósito de la inhumación del despoblado altomedieval de Aistra (Álava). Munibe Antropologia-Arkeologia, 59: 199-217.

Duday, H. 2006. Archaeothanatology or the archaeology of death. In: Gowland, R.; Knusel, C. (eds.). Social archaeology of funeral remains. Oxford, Oxbow Books: 14-29.
Fabião, C.; Guerra, A.; Laço, T.; Melro, S.; Ramos, A. 1998. Necrópole romana do Monte novo do Castelinho (Almodôvar). Revista Portuguesa de Arqueologia, 1: 199220.

Frade, H.; Caetano, J. 1995. Ritos funerários Romanos. In: Medina, J. (ed.). O Mundo Luso-Romano. Amadora, Ediclube, Vol. II: 331-340.

Gonçalves, G.; Maia, C. 2010. Intervenção Arqueológica na Escola Gabriel Pereira (Évora) - Relatório Final. IGESPAR, I.P.

Herrmann, N.; Bennett, J. 1999. The differentiation of traumatic and heat-related fractures in burned bones. Journal of Forensic Sciences, 44(3): 461-469.

Hillson, S. 1996. Dental anthropology. Cambridge, Cambridge University Press.

Hope, V. 2007. Death in ancient Rome - A sourcebook: Routledge sourcebooks for the ancient world. New York, Taylor \& Francis.

Krogman, W.; İşcan, M. 1986. The human skeleton in forensic medicine. Springfield, Thomas Books.

Mantas, V. 2010. Ammaia e Civitas Igaeditanorum. Dois espaços forenses lusitanos. In: Basarrate, T. (ed.). Ciudad y foro en Lusitania Romana. Studia Lusitana, 4: 167-188.

Masset, C. 1982. Estimation de l'âge au décès par lês sutures craniennes. Thèse Doctoral, Laboratoire d'Anthropologie Biologique, Université de Paris VII.

Mays, S. 1998. The archaeology of human bones. London, Routledge.

Mckinley, J. 2000. The analysis of cremated bone. In: Cox, M.; Mays, S. (eds.). Human 
osteology in archaeology and forensic science. London, Greenwich Medical Media: 403-421.

Mesquida, M.; Val, E. 1993. La Necrópole Romana de la C/. Virgen de la Misericordia, Valencia. Siglos I a.C.-III d.C. In: BlanCO, J.; Bellard, C.; Bellard, F. (eds.). Actas del Il Congreso Nacional de Paleopatologia. Valencia, Univ. Valencia: 183-193.

Nawrocki, S. 1995. Taphonomic processes in historic cemeteries. In: Grauer, A. (ed.). Bodies of evidence: reconstructing history through skeletal analysis. New York, Wiley-Liss, Inc.: 49-66.

Nicholson, R. 1993. A morphological investigation of burnt animal bone and an evaluation of its utility in archaeology. Journal of Archaeological Science, 20(4): 411-428.

Norén, A.; Lynnerup, N.; Czarnetzki, A.; Graw, M. 2005. Lateral angle: a method for sexing using the petrous bone. American Journal of Physical Anthropology, 128(2): 318-323.

Polo Cerdá, M.; García Prósper, E.; De Haro Pozo, S. 2009. El Ritual de la cremación en Valentia (ss. II a.C.-III d.C.): analisis bioantropológico preliminar. In: Polo Cerdá, M.; García-Prósper, E. (eds.). Investigaciones histórico-médicas sobre salud y enfermedad en el pasado. Valencia, Grupo Paleolab \& Sociedad Española de Paleopatología: 755-761.

Rolo, A. 2010. A Necrópole Romana da Rouca (Alandroal, Évora). Dissertação de Mestrado em Arqueologia, Faculdade de Letras, Universidade de Lisboa.
Scheuer, L.; Black, S. 2000. Developmental juvenile osteology. London, Academic Press. Shipman, P.; Foster, G.; Schoeninger, M. 1984. Burned bones and teeth: an experimental study of color, morphology, crystal structure and shrinkage. Journal of Archaeological Science, 11(4): 307-325.

Silva, F. 2007. Abordagem ao ritual funerário da cremação através da análise dos restos ósseos. Al-madam, Ila série, 15: 40-48.

Silva, F.; Cunha, E.; Gonçalves, V. 2007/2008. Sinais de fogo: análise antropológica de restos ósseos cremados do Neolítico final/Calcolítico do tholos OP2b (Olival da Pega, Reguengos de Monsaraz. Antropologia Portuguesa, 24/25: 109-139.

Smith, B. 1991. Standards of human tooth formation and dental age assessment. In: Kelly, M.; Larsen, C. (eds.). Advances in dental anthropology. New York, Alan R. Liss: 143-168.

Tranoy, L. 2000. La mort en Gaule Romaine. In: Crubézy, E.; Masset, C.; Lorans, E.; Perrin, F.; Tranoy, L. (eds.). Archéologie Funéraire. Paris, Éditions Errance: 105-154.

Ubelaker, D. 1989. Human skeletal remains: excavation, analysis, interpretation. Washington, Taraxacum. 